\title{
Current perspective of histone deacetylase inhibitors: A review
}

\author{
Bhavini K Gharia ${ }^{1, *}$, Jagatkumar Upadhyay ${ }^{2}$, Bhanubhai N Suhagia ${ }^{3}$, Shailesh A Shah ${ }^{4}$ \\ ${ }^{1,2}$ Assistant Professor, ${ }^{3,4}$ Principal, ${ }^{1,4}$ Dept. of Pharmaceutical Chemistry, Maliba Pharmacy College, Uka Tarsadia University, \\ Bardoli, Gujarat, ${ }^{2,3}$ Dept. of Pharmaceutical Chemistry, Dharamsinh Desai University, Nadiad, Gujarat, India
}

*Corresponding Author: Bhavini K Gharia

Email: bhavini.gharia@utu.ac.in

\begin{abstract}
Epigenetic therapeutics are the new generation of chemotherapeutics for treatment of cancer, and histone deacetylase inhibitors have been actively discovered in this category They target the biological processes including the cell cycle, apoptosis, DNA repair, cell cycle control, autophagy, metabolism, senescence and chaperone function. Several families of histone deacetylase (HDAC) inhibitors have been synthesized and evaluated. Their positive effects on the cell cycle have been demonstrated in biological models and in clinical trials. Recently Food and Drug Administration has approved Vorinostat, Romidepsin and Belinostat for oncologic indications of refractory cutaneous and peripheral $\mathrm{T}$ cell Lymphoma. These advances have provided the motivation to develop more potent and selective inhibitors and target other pathologic conditions with these drugs. Major ongoing efforts are to develop inhibition as monotherapy, rational combination with chemotherapy and other targeted drugs. Some progress is made into developing isoform specific drugs. In this perspective, the biological functions and potential substrates of histone deacetylase enzymes are reviewed and the characteristics of this inhibitors are discussed in respect with anticancer activity and further therapeutic interest.
\end{abstract}

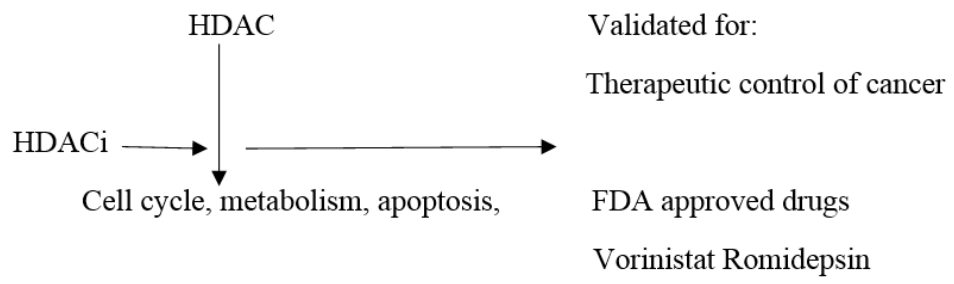

Keywords: Epigenetic therapeutics, Histone deacetylase inhibitors, Anticancer, Classification, Food and drug administration approved drugs.

\section{Introduction}

Epigenetic changes are sometimes cause of cancer because they cause the silencing of certain genes, while permitting transcriptional changes to other genes. It result in differences from the parent cell line, damage of cell regulation and cell immobilization. ${ }^{1-7}$ The study in phenotype without the corresponding change in genotype is thus termed as Epigenetics. It comprises modifications in heritability of phenotype from a particular cell to an entity. A group of key players in transcriptional regulation are two group of enzymes that are histone acetyl transferases (HATs) and histone decetylases (HDACs) that regulates the $\mathrm{N}-\varepsilon$-lysine acetylation and deacetylation of histone. ${ }^{1,2}$ Histone deacetylase inhibitors may activate or inactivate or modulate the activities of biological cell cycle., Therefore histone deacetylase inhibitors are the main targets for treating human disorders such as cancer, parasitic and inflammatory diseases. In this review, inhibitors primarily acting on cancerous cell are described along with drugs in clinical use as well as those molecules which are under development.

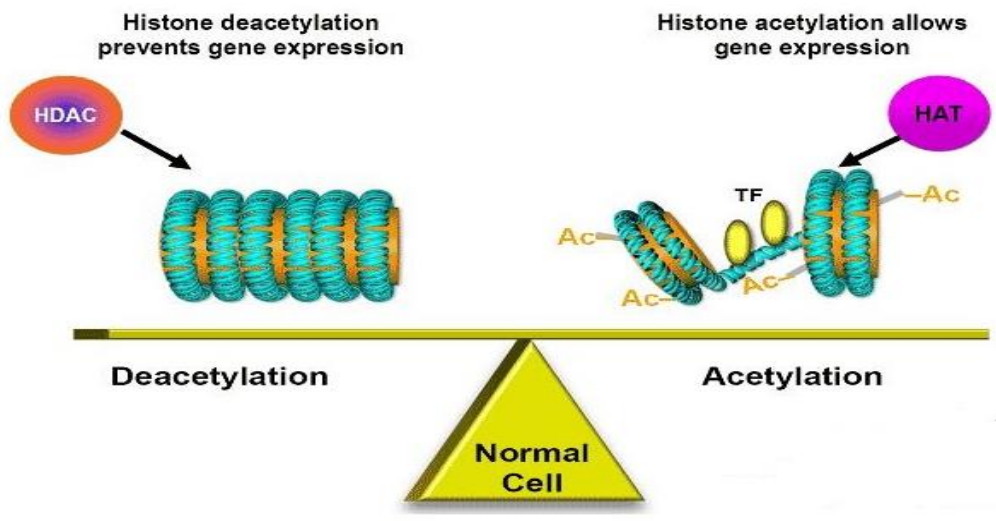



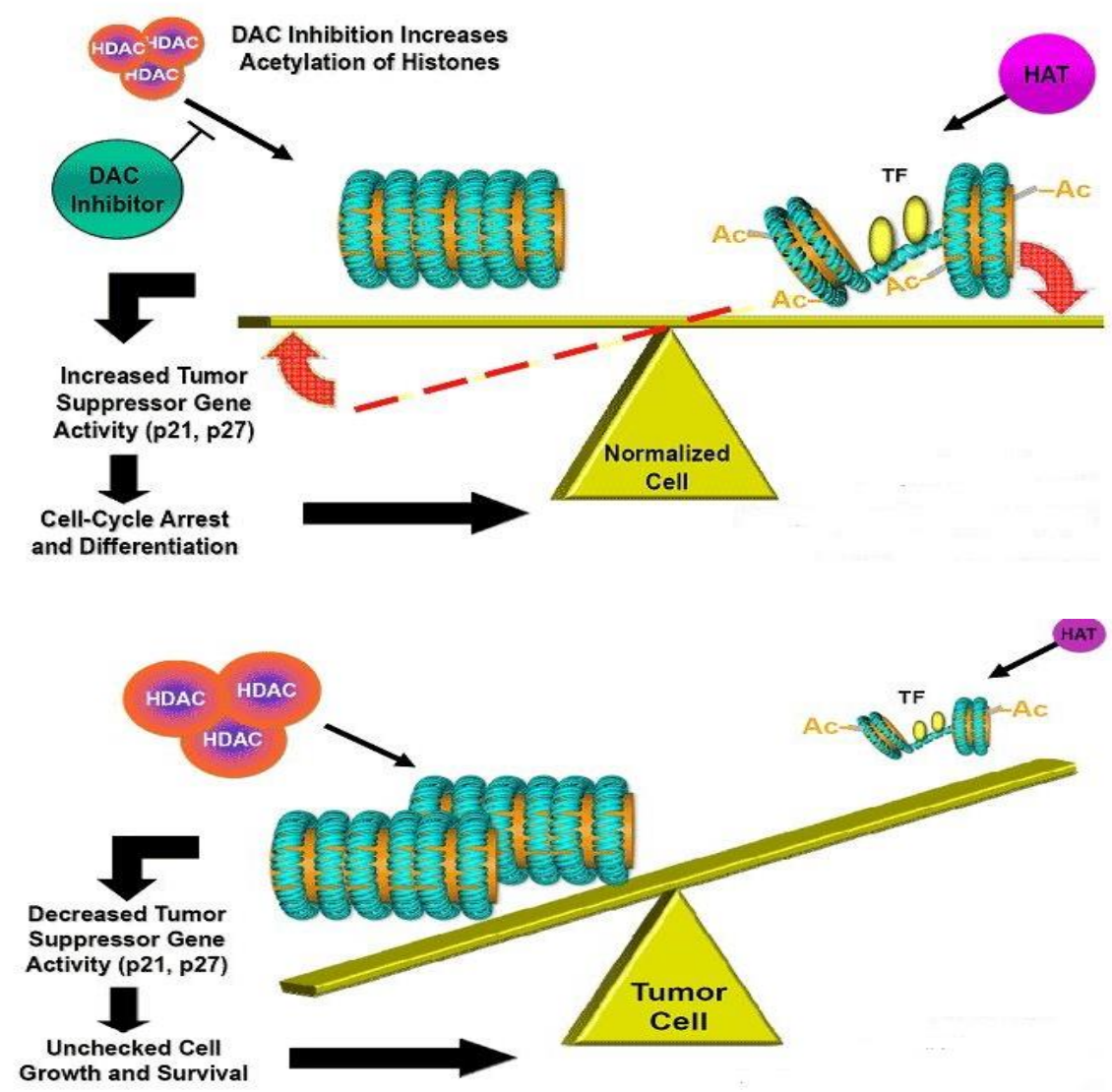

Fig. 1: The balance of histone acetylation and deaceylation

The level of histone tail acetylation which determines the chromatin state is the result of the completing actions of histone acetylase and histone deacetylase enzymes. Histone deacetylase inhibitors change this balance by inhibiting that enzyme, thereby resulting in increased in histone acetylation. Histone acetylase and histone deacetylase two classes of enzyme work in opposing direction either by the transfer of acetyl group from acetyl Co A with the help of histone acetylase (HATs) or removing acetyl group with histone deacetylase (HDACs) from lysine residue of histone tails. ${ }^{5,6}$ Disturbance of Histone acetylase transferase (HAT) and Histone deacetylase (HDACs) activities has been connected with the increase of a varied range of human cancers. Histone deacetylase (HDACs) inhibitors cause o increase of the acetylated level of histones, which in turn stimulate the reexpression of silenced controlling genes in cancer cells and inverse the malignant phenotype. Outstanding to this influence, Histone deacetylase (HDACs) inhibitors have recently emerged as potential cancer therapeutic agents.

Proteic Characteristics and Classification of HDAC Inhibitors: The basic unit of chromatin is the nucleosome, which comprises of 147 base pairs of DNA super helix wrapped around the histone core consisting of two copies each of core histones. Histones are the primary protein components of chromatin of five classes (H1, H2A, H2B, H3 and $\mathrm{H} 4)$. $\mathrm{H} 1$ is a linker histone and the remaining are core histones. The core plays an important role in establishing interactions between the nucleosomes and within the nucleosome particle itself. The $\mathrm{N}$ terminals of core histones are flexible and unstructured, but the rest are predominantly globular and well structured. Chromatin adopt diverse conformational changes which subject on epigenetic alterations in DNA and in histone tails that device initiation or suppression of gene transcription. There is existent of eight distinct histone post transcriptional modifications which are acetylation, methylation, phosphorylation, ubiquitylation, sumoylation, $\mathrm{AD}$ Pribosylation, deamination and proline isomerization.

In eukaryotic cells, DNA wraps around histone proteins, creating complexes called nucleosomes that are packed inside the nucleus. How tightly the negatively charged DNA is wrapped around histones depends on acetylation state on histone lysine residue, particularly on histone $\mathrm{H} 3$ and $\mathrm{H} 4 .^{7,8}$

HATs add an acetyl group from acetyl co A to the lysine amino group which reduces the positive charge on the histones. When histone are acetylated, the DNA is more loosely wrapped leading to gene activation. HDACs on the other hand cause deacetylation, resulting 
in positively charged histones that are more tightly wrapped by DNA. Histone deacetylation is correlated with gene repression. The mechanism of action of HDAC inhibitors seems to be multifaceted. HDACs inhibitors are thought to reduce the deacetylation levels of histone proteins that are over expressed in cancerous cells. HAT/HDAC enzymes are capable of regulating both histone and non-histone proteins. Therefore they are able to exert their therapeutic activity through both histone and non-histone pathways. ${ }^{9,10}$

Inhibitors of HDACs enzymes are known to induce cell cycle arrest, p53 independent induction of cyclin dependent kinase inhibitor p21, tumour selective apoptosis and differentiation of normal and malignant cells. So, this direct and indirect effect of HDAC enzyme on tumour cells and metastasis make histone deacetylase inhibitors (HDACi) as potential class of anticancer agents. ${ }^{11,12}$ There are two major pathways of apoptosis, first "extrinsic pathway" or death receptor pathway and second is "intrinsic pathway" or mitochondrial pathway. All HDAC inhibitors have been reported to follow either one or both of these cell death pathways in many cancer models. The proposed mechanisms of cancer cell death resulting from HDAC inhibitor treatment are as following:

1. Death receptor (Extrinsic) pathway of apoptosis

2. Mitochondrial (Intrinsic) pathway of apoptosis

3. Inhibition of angiogenesis

4. Generation of reactive oxygen species

\section{Autophagy, etc.}

Intrinsic pathways are triggered by disruption of mitochondrial membranes in cellular stresses such as chemotherapy, ionizing radiation and withdrawal of growth factors and Extrinsic pathway is originated by binding of ligands, such as Fas ligand (Fas L), tumor necrosis factor (TNF) and TNF - related apoptosis inducing ligand (TRAIL) to their respective cell surface death receptors (DR).

Histone deacetylase inhibitor can also block tumor angiogenesis by reserving of hypoxia inducible factors (HIF) mechanism. Hypoxia controls gene expression of Vascular Endothelial Growth Factor (VEGF) by alleviating the transcription factor HIF $1 \alpha$ where as tumor suppressor gene Von Hippel Lindua (VHL) damages HIF $1 \alpha$. They disrupt heat shock protein 90 (Hsp90) mediated chaperone function and expose HIF $1 \alpha$ to proteosomal degradation which contribute to the anti-angiogenic pathway. HDAC inhibitors indirectly damage DNA by encouraging changes in chromatin conformation upon histone acetylation. It might expose the DNA to UV rays, ionizing radiation, reactive oxygen species and chemotherapeutic genotoxic chemicals. ${ }^{13-15}$

Generation of reactive oxygen species (ROS) is another key event in this inhibitor to induced cell death, causing DNA damage. Free radical scavengers like Nacetyl cysteine reduce generation of reactive oxygen species which leads to cell death. ${ }^{16,17}$

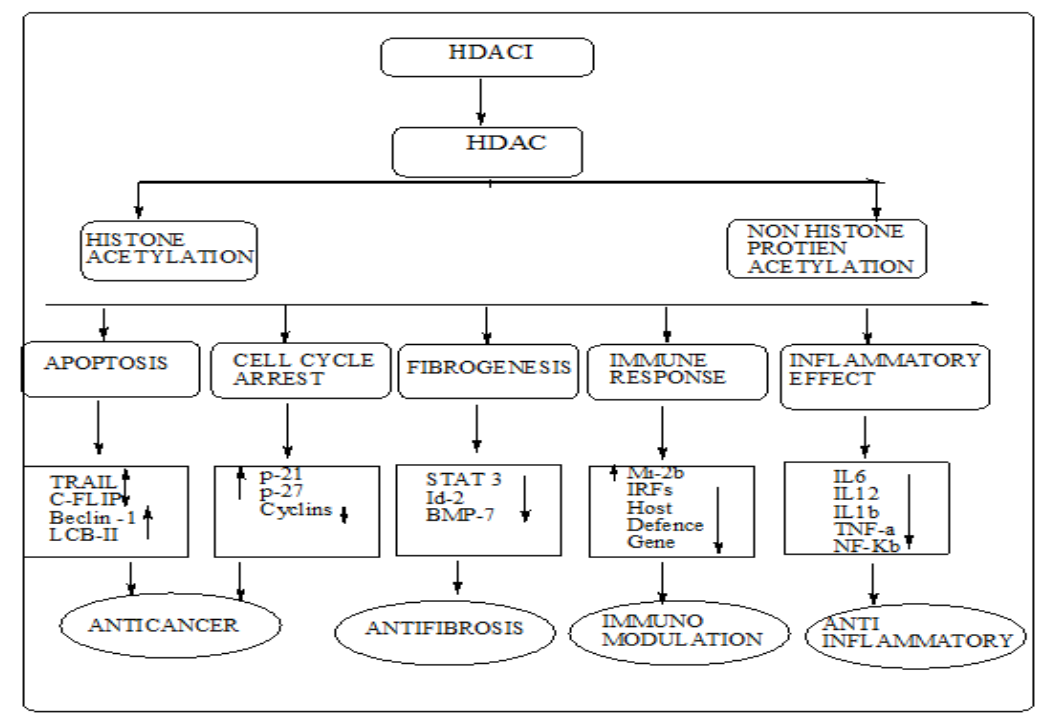

Fig. 2: Mechanism of histone deacetylase enzyme

Initial Development of HDAC in Clinical use of Cancer: There are four classes of HDAC on their sequence homology to saccharomyces cerevisiae HDACs. ${ }^{18,19}$ Eighteen distinct human HDACs are grouped in this four main category. The HDAC family is divided into $\mathrm{Zn}$ dependent (Class I and Class II) and NAD -Dependent (Class III) enzymes. The Zndependent enzymes have been the focus of intense research, while the Sir 2 family recently implicated in acetylation and regulation of key cell cycle proteins such as p53. Till date, eleven HDAC family members in classes I and II are characterized .i.e. HDACs 1,2,3,8 are class 1 and HDACs 4-7,9,10 are class II, a grouping based on the sequence similarity. The most recent identified member of HDAC family is HDAC 11 comprising in Class IV. 
Table 1: Classification of histone deacetylase enzyme

\begin{tabular}{|l|c|c|}
\hline Zn dependant HDAC & NAD-dependant HDAC & \\
\hline Inhibited by Trichostatin A(TSA) & Inhibited by nicotinamide & \\
\hline Class I & Class II & Class III \\
\hline HDAC 1 & HDAC 4-7 & SIRT 1-7 \\
\hline HDAC 2 & HDAC 9 & \\
\hline HDAC 3 & HDAC 10 & \\
\hline HDAC 8 & & \\
\hline HDAC 11 & & \\
\hline
\end{tabular}

Class I family are homologous to yeast RPD-3 (reduced potassium dependency-3). They share a compact structure. They are predominantly nuclear proteins and ubiquitously expressed in most tissues and cell lines. Class II are homologous to yeast HDA-1protien (Histone deacetylase-1). It can be subdivided into two subclasses. Class IIa (HDAC 4,5,7,9) have one catalytic domain and long amino terminal adapter domain. Class II b (HDAC 6, HDAC 10) have two catalytic domain. Class II family HDACs are mainly confined in the cytoplasm, however depending upon the phosphorylation status they are split between the cytoplasm and nucleus. Class III inhibitors are also known as sirtuins as they comprise of seven members and they share sequence homology with yeast silent information regulator-2 (Sir-2) protein. They do not contain zinc and their activity require nicotinamide adenine dinucleotide $\left(\mathrm{NAD}^{+}\right)$. Sirtuins (SIRTs) are found in three important cellular compartments: nucleus, cytoplasm and mitochondrion. Phylogenetically SIRTs are distributed into four classes (SIRT 1, SIRT 2 and SIRT 3 belong to class 1, SIRT4 to class-II, SIRT 5 to Class III, and SIRT6 and SIRT7 to class IV.) HDAC 11 has conserved residues in its catalytic center that are shared by both class I and Class II deacetylase and placed in Class IV. ${ }^{20,21}$

This review provide broad information on Structure activity relationship (SAR) development of this inhibitors and their modelling and binding mode of inhibitors are studies. The model propose that cap, zinc binding site and saturated or unsaturated linker that are essential pharmacophoric feature in the core scaffold.

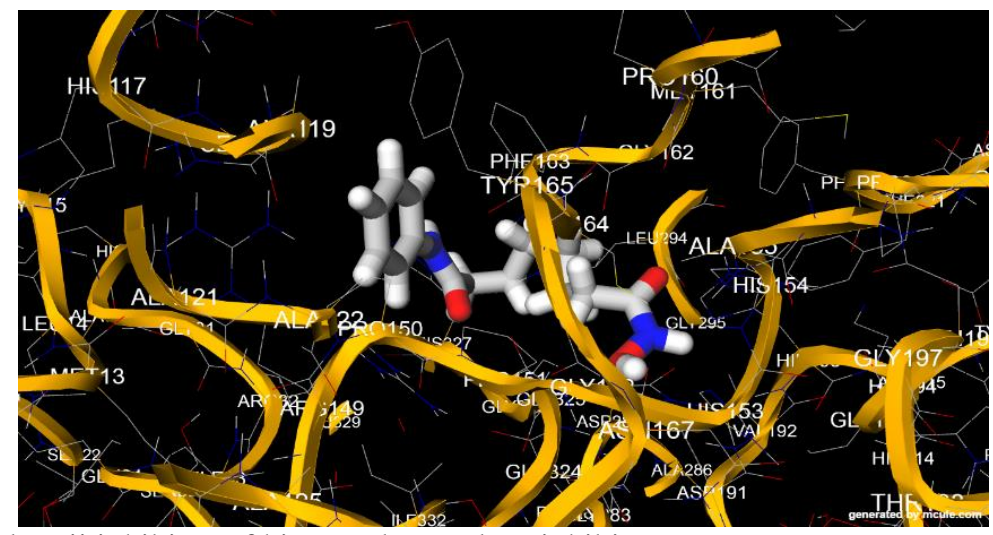

Binding inhibition of class ii inhibitor of histone deacetylase inhibitor

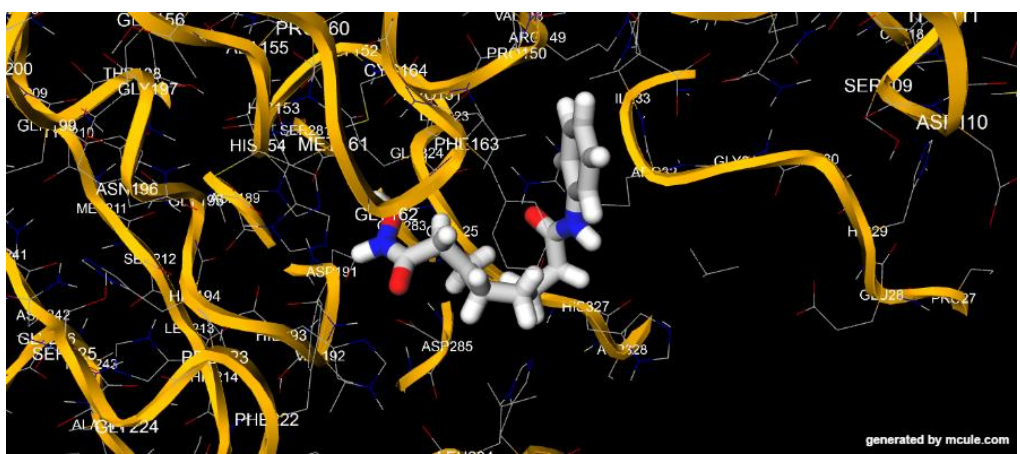

Binding inhibition of class iii inhibitor of histone deacetylase inhibitor

Fig. 3: Amino Acids involved in the binding of inhibitors 


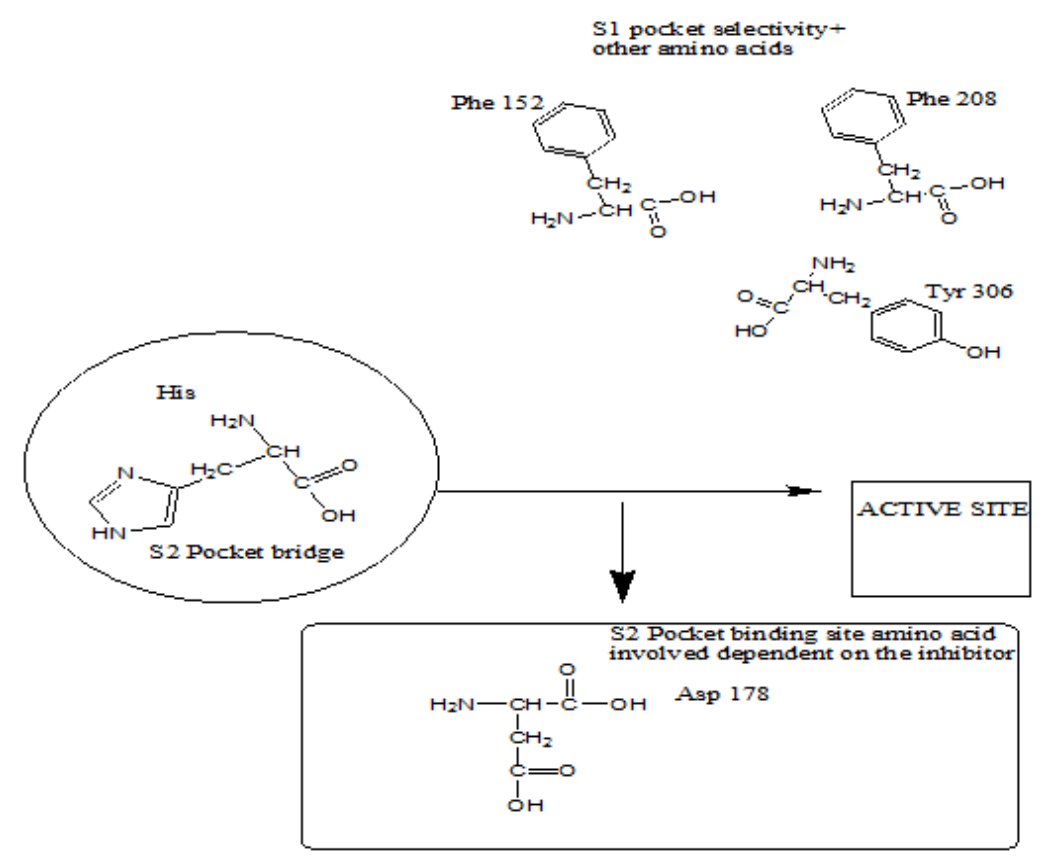

Fig. 4: Systematic representation of amino acid interaction in the pockets

As shown in the Fig. 4, there are different binding regions that are represented by S1 and S2 pockets. As shown in the figure, $\mathrm{S} 1$ pocket contains amino acid such as Phe152, Phe 208, Tyr 306 which represents the hydrophobic site. The S2 pocket is involved in bridge formation with the interactions with the cationic group and in the main binding site involving the residue Asp 178 and Asp267. Because of the large diversity of the chemical structures that able to inhibit HDAC, each inhibitor will display a slightly or largely different mode of binding than this inhibitor, involving other amino acids.

\section{Basic Structure of Zinc Binding HDAC Inhibitors}

Most of zinc-dependent HDAC inhibitors have common pharmacophore consisting of three distinct features which are as follows.

1. Cap group or surface recognition unit, usually a hydrophobic and aromatic group, which interacts with the rim of the binding pocket.

2. Zinc binding domain (ZBD) such as hydroxamic acid, carboxylic acid or benzamide groups, which coordinates to the active site of $\mathrm{Zn}^{+2}$ ion.

3. A saturated or unsaturated linker domain with the linear or cyclic structure, that connects the cap group to the $\mathrm{ZBD}{ }^{22}$

Crystallographic analyses of HDAC in complex with hydroxamate compounds have revealed that the capping group is solvent exposed and interacts with the amino acid near the entrance of the active site, whereas the metal binding moiety resides in the interior of the protein and forms complexes with the metal ion. The linker serves to position the capping group and the metal binding domain appropriately for providing high affinity interactions with the proteins. ${ }^{23}$

It shows the pharmacophoric summary and structure of a few selected HDAC inhibitors. The cap group, linker and the zinc binding domain (ZBD) are indicated by coloured purple, yellow and brown respectively.<smiles>O=C(CCCCCCC(=O)Nc1ccccc1)NO</smiles>

Fig. 5: Pharmacophore of vorinostat (FDA approved drug)

The selectivity and potency in these various inhibitors depend on variations in any or all three domains. Binding modes of these inhibitors have been proposed, (Fig. 6) containing different groups such as: organic hydroxamic acids analogues, short chain fatty acids analogues, benzamides analogues, cyclic tetrapeptides analogues and sulphonamide anilides analogues. The extensive study of structure activity relationship of this inhibitors can be summarized as below.

The zinc binding domain acts as metal binding moiety for the attachment of various substituents. It contains various functional groups such as hydroxamic acids, benzamides, thiols, ketones or epoxides. Modifications of the linker group with different chain length can be done including aliphatic (in vorinostat drug), aromatic substitution (Belinostat drug) or cyclic substitutions (in Depsipeptide drug). 
The cap region contains aromatic groups such as benzene, pyridine and several fused bicyclic heterocycles. Comparing the inhibitory activity $\left(\mathrm{IC}_{50}\right.$ value) of different inhibitors containing different functional moiety it was found that hydroxamate having IC50 value of $110-370 \mathrm{nM}$ was changed to $52 \mathrm{nM}$ in depsipeptide, $2 \mu \mathrm{M}$ in case of entinostat drug containing
Benzamide functional group and $50 \mu \mathrm{M}$ in case of valporic acid having carboxylic group. Hence, it was observed that hydroxamic acid have more potent activity compared to other functional groups such as benzamide and carboxylic acid groups attached to the main analogue.
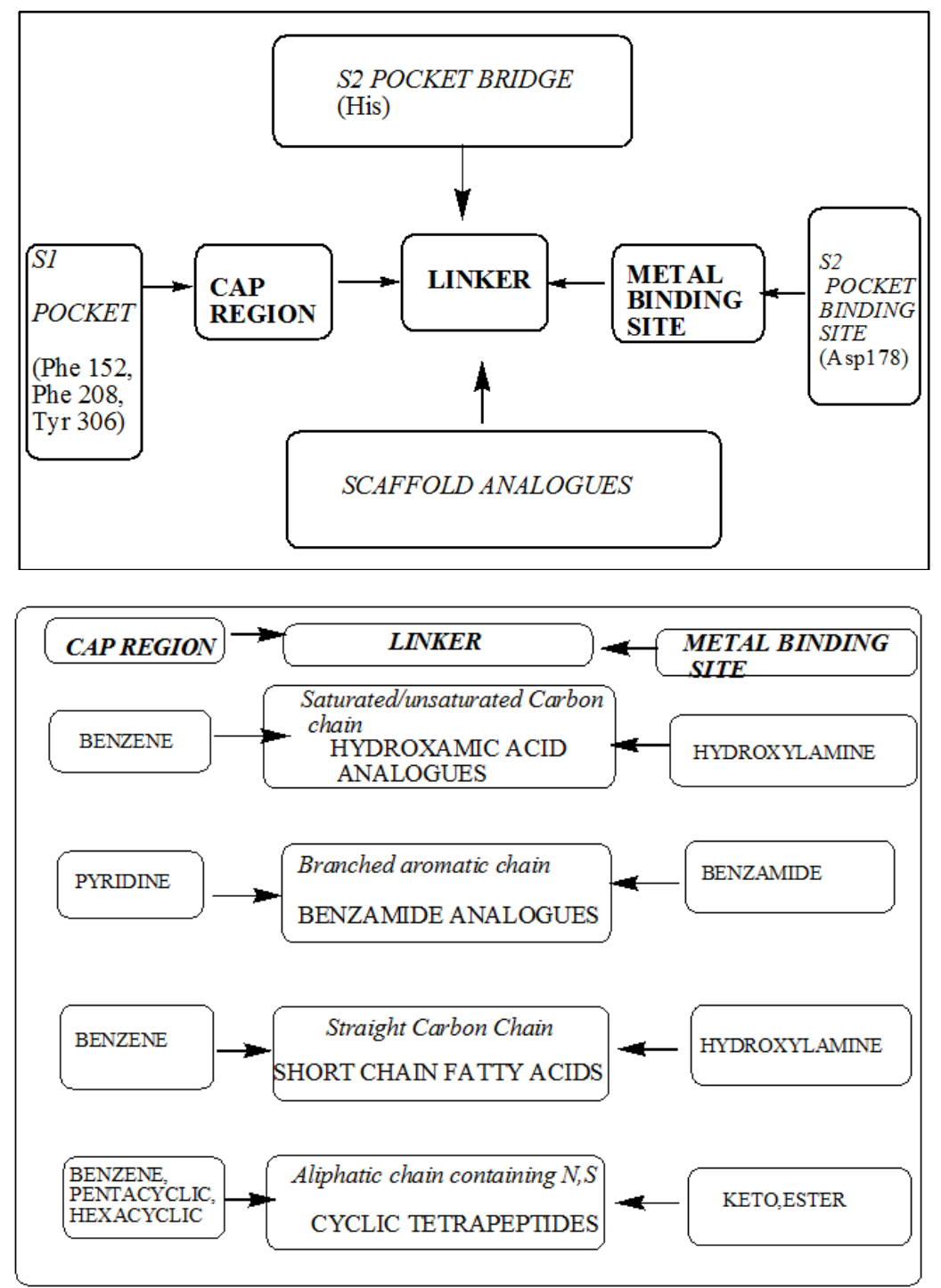

Fig. 6: Binding mode of different scaffold based analogues in histone deacetylase inhibitor enzyme

Hydroxamic acid group are the first classes of histone deacetylase inhibitors. The first biological confirmation of HDAC as a therapeutic target was provided by its $X$ ray crystallography. The results then permitted for the synthesis of new hydroxamic analogues with optimized properties by several academic and industrial groups. Considering the selectivity of HDAC inhibitors, heterocyclic ring were designed in the metal binding site. Later on, several other analogues such as depsipeptide, benzamide and fatty acid chain were synthesized. Depsipeptide is a molecule that has both peptide and ester linkage in the same amino acid attached with small molecule or a chain. The ester moiety is generally accomplished with synthetic alteration, making depsipeptide easy to prepare for proteolytic enzymes. Similarly benzamide moiety with amino and hydroxyl group shown good inhibitory activity on the enzyme. Studies revealed that anilide moiety was found to have slow effect on the enzyme. ${ }^{32}$ Recently short chain fatty acid also shown inhibitory effect on histone deacetylase enzyme. 
Table 2: List of clinically approved inhibitors

\begin{tabular}{|c|c|c|c|c|c|c|}
\hline Name & $\begin{array}{c}\text { IUPAC } \\
\text { Name }\end{array}$ & Code Name & $\begin{array}{l}\text { Trade } \\
\text { Name }\end{array}$ & $\begin{array}{l}\text { Chemical } \\
\text { Structure }\end{array}$ & Ref & $\begin{array}{l}\text { Company/ } \\
\text { Approval }\end{array}$ \\
\hline $\begin{array}{l}\text { Vorinostat } \\
\text { (1) }\end{array}$ & $\begin{array}{c}N \text {-Hydroxy- } \\
N^{\prime} \text {-phenyloctane } \\
\text { diamide }\end{array}$ & $\begin{array}{c}\text { suberanilohydroxamic } \\
\text { acid }\end{array}$ & Zolinza & & 27 & $\begin{array}{c}\text { Merck } \\
\text { (2006) } \\
\text { USA }\end{array}$ \\
\hline $\begin{array}{l}\text { Depsipeptide } \\
\text { (2) }\end{array}$ & $\begin{array}{c}1 S, 4 S, 7 Z, 10 S, 16 E, 2 \\
1 R)-7 \text {-ethylidene- } \\
4,21 \text {-diisopropyl-2- } \\
\text { oxa- } \\
\text { 12,13-dithia-5,8,20, } \\
\text { 23tetrazabicyclo } \\
\text { [8.7.6]tricos-16 } \\
\text {-ene-3,6,9,19,22- } \\
\text { pentone }\end{array}$ & Romidepsin & Istodax & & $28-29$ & $\begin{array}{c}\text { Gloucester } \\
\text { Pharmaceuticals } \\
\text { (2009) } \\
\text { USA }\end{array}$ \\
\hline $\begin{array}{l}\text { Belinostat } \\
(3)\end{array}$ & $\begin{array}{c}(2 E)-N \text {-Hydroxy-3 } \\
-[3- \\
\text { (phenylsulfamoyl) } \\
\text { phenyl }] \\
\text { prop-2-enamide }\end{array}$ & PXD 101 & $\begin{array}{c}\text { Beleoda } \\
\mathrm{q}\end{array}$ & & $30-38$ & $\begin{array}{c}\text { Spectrum } \\
\text { Pharmaceuticals } \\
\text { Inc. } \\
\text { (2014) } \\
\text { USA }\end{array}$ \\
\hline $\begin{array}{l}\text { Panobinostat } \\
\text { (4) }\end{array}$ & $\begin{array}{c}2 E)-N \text {-hydroxy-3- } \\
\text { [4-(\{[2-(2-methyl- } \\
1 H \text {-indol-3- } \\
\text { yl)ethyl]amino }\} \\
\text { methyl)phenyl }] \text { acryl } \\
\text { amide }\end{array}$ & LBH -589 & Farydak & & 39 & $\begin{array}{c}\text { Novartis } \\
(2015) \\
\text { USA }\end{array}$ \\
\hline
\end{tabular}

Compound 1 is the first inhibitor used in the treatment of Cutaneous T Cell Lymphoma (CTCL) and sanctioned by Food and drug administration (FDA). After these clinical trials, numerous clinical trials for these inhibitors have been accompanied, resulting in the approval and marketing of compound 2 and compound 3 inhibitors

The biological characteristics of this inhibitors differ. Compound 1 is used in phase I and phase II clinical trials for haematological malignancies and solid tumors $^{27}$. Maximum tolerated dose is $400 \mathrm{mg}$ once daily or $200 \mathrm{mg}$ twice daily. Compound 2 is bicyclic peptide isolated from chromobacterium violaceum and demonstrated potent in vitro cytotoxic activity against human tumor cell lines and in vivo efficacy against human tumor xenograft. It is a unique HDAC inhibitor prodrug. Dose $17.8 \mathrm{mg} / \mathrm{m}^{2} /$ day is recommended. ${ }^{28} \mathrm{In}$ the search for the biologically stable HDAC inhibitors containing benzamide functional group compound 3 was developed. It was investigated in many cell lines which include hepatocellular carcinoma, human cancer, chronic lymphocyctic leukemia, prostate cancer, bladder cancer and ovarian cancer cells in. ${ }^{31-37}$ Maximum tolerated dose(MTD) is $1000 \mathrm{mg} / \mathrm{m} 2$ /day. Compound 4 is a novel hydroxamate analogue. It demonstrated acetylation of histone $\mathrm{H} 3$ and $\mathrm{H} 4$ by increasing P21 levels, disrupting chaperone function of hsp90, induce cell cycle G1 phase accumulation and apoptosis of K562 cells and acute leukemia MV4-11 cells. $^{38}$ The anti tumor effect of this drug was demonstrated in multiple myeloma, NSCLC as well as castrate -resistant prostate cancer cell lines. Phase I clinical study with oral compound 4 alone or in combination with docetaxel is also completed. It is being tested against Hodgkin's lymphoma and cutaneous T-cell lymphoma as well as other types of cancer. They can block androgen receptor-mediated transcriptional activation of many genes and thus may result in possible benefit in treating Castration resistant prostate cancer. ${ }^{39}$

More Recent HDAC Inhibitors under Development: The clinical success of the FDA approved drugs following the initial approval of Vorinostat has also stimulated the field to develop and evaluate additional HDAC inhibitors in order to obtain the drugs with improved properties. Several excellent recent reviews have been published covering the development of potential new therapeutic HDAC inhibitors. Several new molecules have reached different phases of clinical trials (Table 3) or are in preclinical evaluation. 
Table 3: List of inhibitors in ongoing clinical studies

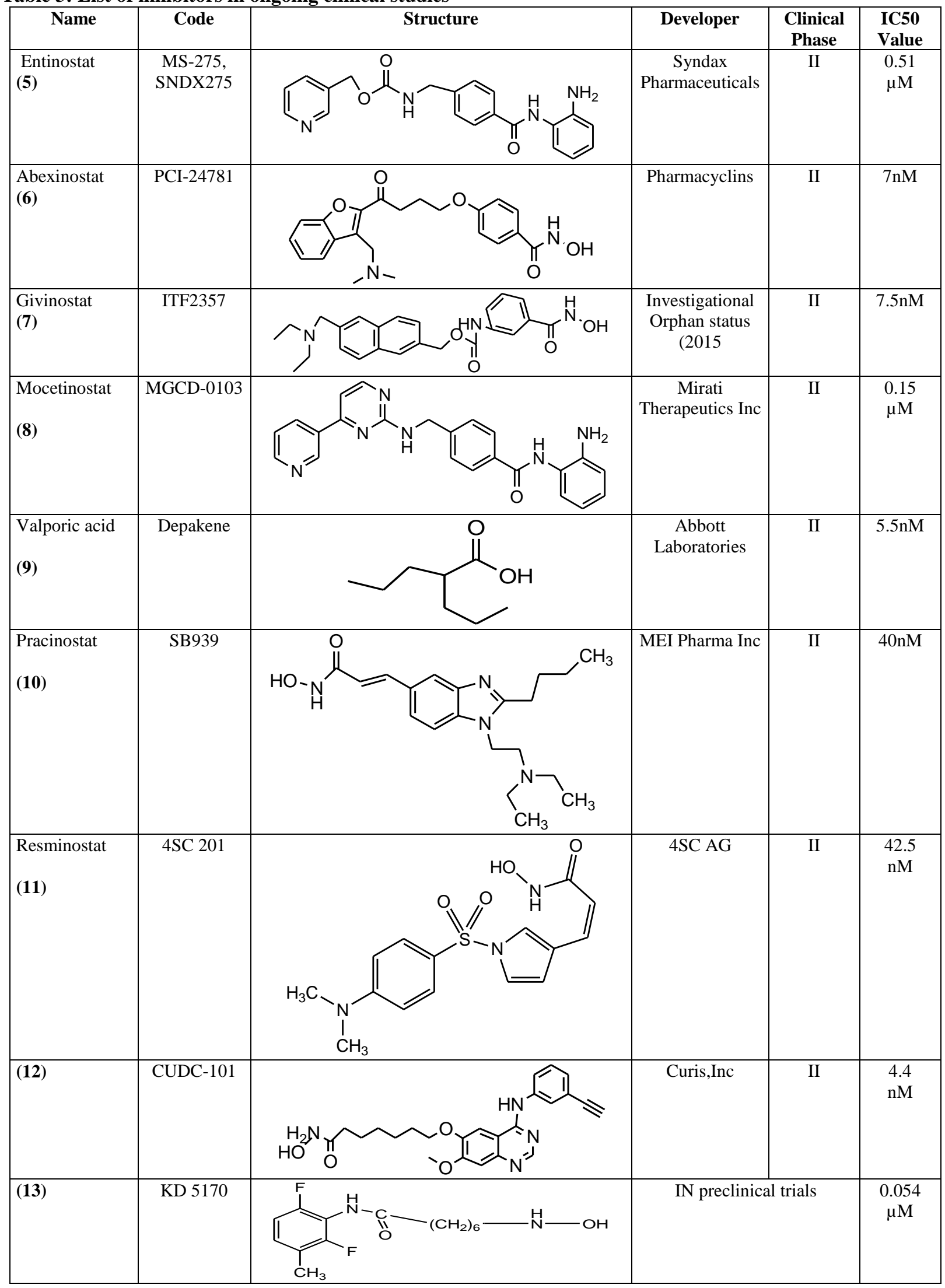


Compound 5 is synthetic benzamide derivative that inhibits HDACi and used to treat patient with leukemia, lymphoma or solid tumors in phase I, II clinical trails. ${ }^{40}$ Maximum Tolerated Dose is $10 \mathrm{mg} / \mathrm{m}^{2} /$ day. Pre-clinical studies suggested that combining inhibitors of DNA methyltransferase (DMT), 5-azacitidine (ADA), with inhibitor of HDAC, SNDX-275, synergistically induced re-expression of epigenetically -silenced tumor suppressor genes and had antitumour effect. Clinical study revealed that it is safe and well tolerated in patients with advanced non small cell lung carcinoma. Maximum tolerated dose is $10 \mathrm{mg} / \mathrm{m}^{2}$.Dose limiting toxicity were gastrointestinal side effects and fatigue. Clinical studies have examined the activity of entinostat in cancer cells, which include renal cell cancer, colon cancer and metastatic melanoma, non-small cell lung cancer, breast cancer and lymphoblastic leukemia,. This class I selective HDAC inhibitor is well accepted either as a single agent or in combination with other drugs.

Compound 6 is formerly CRA 024781. It is phenyl hydroxamic acid which is evaluated alone or with ionizing radiation and other DNA-damaging agents in pre-clinical studies. It act by preventing DNA repair resulted in synergistic effect on apoptosis when combined with other agents. ${ }^{41-43}$ Phase I clinical trials in refractory advanced solid tumor patients revealed that it was well accepted in following iv or oral route. And it is not dose-related. Mean oral bioavailability was observed to be $0.28 \%$. Tubulin and histone acetylation were recognized in peripheral blood mononuclear cells (PBMCs).

Compound 7 is synthesized inhibitor containing a hydroxamic acid linked to aromatic ring. Studies are going on in Phase II clinical study. Many reports have shown that it has inhibitory activity in production of pro inflammatory cytokines, as well as cytotoxic activity both in-vitro on several human tumour cell lines and invivo in patients with hematologic malingnancies. ${ }^{44-48}$

Compound 8 is novel isotype selective inhibitor of human HDACi with potential to regulate aberrant gene expression. Phase I/II study with MGCD-0103 alone or combination with genecitabine were done in patients with solid tumors recently. Phase I of clinical trial was studied in refractory solid tumors. Phase II study was done with advanced or metastatic pancreatic cancer. Maximum Tolerated Dose is recommended $90 \mathrm{mg}$, and is ongoing in patients with pancreatic cancer. ${ }^{50}$

Compound 9 is currently used for the treatment of breast cancer, thyroid, lung, ovarian, bladder, head and neck, pancreatic, brain and leukemia cancers. In phase I study, a sequence specific combination of valproic acid and epirubicin in solid tumor malignancies was done. A phase II study of hydralazine and valproic acid in treating patients with advanced solid tumors revealed clinical benefit. Valporic acid shows the good oral bioavailability. $50 \mathrm{mg} / \mathrm{kg}$ daily dose of valproic acid is given. ${ }^{51-53}$
Compound 10 is in phase II study and tolerated in patients with intermediate or high risk myelofibrosis (MF). This compound is another hydroxamate based inhibitor. This compound was shown to have clinical benefit and modest activity in patients with MF. ${ }^{54}$

Compound 11 is evaluated in a pharmacokinetics and pharmacodynamics phase I study in patients with the advanced solid tumors, yielding a suggested phase II dose of $600 \mathrm{mg} /$ day. Low micro molar concentartions of resminostat lead to cell growth and strongly induced apoptosis in multiple myeloma (MM) cell lines. Synergistic efforts was observed with melphalan, bortezomib and S-2209.

Compound 12 has shown that simultaneous inhibition of HDAC and receptor tyrosine kinases (epidermal growth factor receptor-EGFR-and human epidermal growth factor receptor-2-HER2) in cancer cells, displayed antiproliferative and proapoptotic activities in vitro as well as in drug -resistant in vivo tumor models. This synergistic inhibition was also tested in patients with advanced solid tumor using this compound, and the drug was found to induce histone $\mathrm{H} 3$ acetylation in some of the patients. This study recommended a dose of $275 \mathrm{mg} / \mathrm{m}_{2}{ }^{55}$

Compound 13 is a mercaptoketone based class I and II HDAC inhibitor having thioester prodrug demonstrated with broad spectrum cytotoxicity against a range of human tumor-derived cell lines. In the proposed mechanism of action, the thioester prodrug undergoes hydrolysis to generate mercaptoketone that coordinates $\mathrm{Zn}^{+2}$ in a bidentate or monodentate fashion in the active site of HDACs. ${ }^{56}$

Histone deacetylase inhibitors are the chemical compounds that inhibit histone deacetylase. A drug is classified into many categories depending on its chemical nature and function. Hence, various different category of histone deacetylase inhibitors are made.

\section{Chemical Structure Classification}

Most of the available inhibitors possess a three part structure consisting of a zinc binding group that inserts in the active site, linker and a moiety that interact with residues near the entrance to the active site. The classical inhibitors acts entirely on class I and Class II inhibitors by binding to the zinc containing catalytic domain of HDACs. A larger number of natural and synthetic compounds function as inhibitors. Several classes of inhibitors have been identified, including (a) organic hydroxamic acids (b) short chain fatty acids (c) benzamides (d) cyclic tetrapeptides (e) sulphonamide anilides.

\section{Different Classes of HDAC Inhibitors}

Hydroxamic Acid Derivatives: Hydroxamic acid based derivatives vorinostat is well tolerated in patients with Cutaneous $\mathrm{T}$ Cell Lymphoma, and observed promising anti-cancer activities in different types of cancer, such a diffuse large B-cell lymphoma, 
Hodgkin's lymphoma and other haematological and solid tumors. Given the diverse anticancer activity, much efforts has been made to explore hydroxamic acid derivatives such as entinostat, belinostat, givinostat, practinostat and others as potential treatment for various cancer cells. ${ }^{57}$

Cyclic Peptides: Romidepsin is bicyclic peptide isolated from chromobacterium violaceum and demonstrated potent in vitro cytotoxic activity against human tumor cell lines and in vivo efficacy against human tumor xenograft. Natural cyclopeptide FR235222 isolated from the fermentation broth of Acremonium sp. Caused accumulation of acetylated histone H4, inhibition of human leukemia cell (U937) proliferation, and cell cycle arrest in the GI phase via p21. Other antural cyclopeptides to act as HDAC inhibitors are chlamydocin from Diheterospora chlamydosporia, apicidin from Fusarium sp. and the microbial metabolite trapoxin. ${ }^{58}$

Benzamide Derivatives: Benzamide containing HDAC inhibitors are another class of compounds that exhibited both in vitro and in vivo anticancer activities. Among them Mocetinostat, Entinostat, Givinostat and Mocetinostat are examples of benzamide derivatives that had been taken into clinical trials. ${ }^{59}$

Short Chain Fatty Acids: These compounds represent another class of HDAC inhibitor with simple structures that showed clinical potential in various studies. Valporic acid and phenyl butyrate are two well characterized compounds that belong to this class of compounds. They both display inhibition for class I and Class IIa inhibitors. It was proved that hydroxamic acid based HDAC inhibitors are found to be more potent in inhibiting the activity than this drugs. ${ }^{60}$

\section{Miscellaneous}

Epoxide based Histone Deacetylase Inhibitors: Epoxides are another known group of inhibitors of zinc dependent HDAC enzymes. Epoxide bearing natural compounds such as trapoxins and depudecin are reported to form covalent bonds with HDACs. The HDAC activity of these compounds occur at micro molar to nano molar concentrations. Depudecin is a microbial metabolite containing two epoxide groups, whereas trapoxin has only one epoxide group. ${ }^{61}$

Thioester based Histone Deacetylase Inhibitor: Thioesters are used as prodrug strategies. Largazole is a depsipeptide with the thioester moiety purified from marine cyanobacteria called cyanobacterium symploea $s p$ and it is a class I selective HDAC inhibitor. Largazole upon protein assigned hydrolysis liberates the bioactive largazole thiol. Disulfide prodrug strategy to modulate largazole based compounds resulted in enzymatic activities comparable to the natural product largazole.

Electrophilic Ketone based Histone Deacetylase Inhibitor: Trifluoromethyl ketones are known to be readily hydrated and have been reported as potent inhibitors of aspartyl, cysteine and serine proteases, as well as zinc dependent enzymes. Trifluoromethyl ketones attached to aromatic amides showed micro molar inhibitory activities as HDAC inhibitors in breast and fibro sarcoma cell lines. Similarly cyclic tetra peptides containing trifluoromethyl and pentafluoromethyl ketones as zinc binding functional groups were also found to be potent HDAC inhibitors with promising anticancer activities. ${ }^{62}$

Table 4: It shows various structures of HDAC inhibitors along with its detailed chemical classification

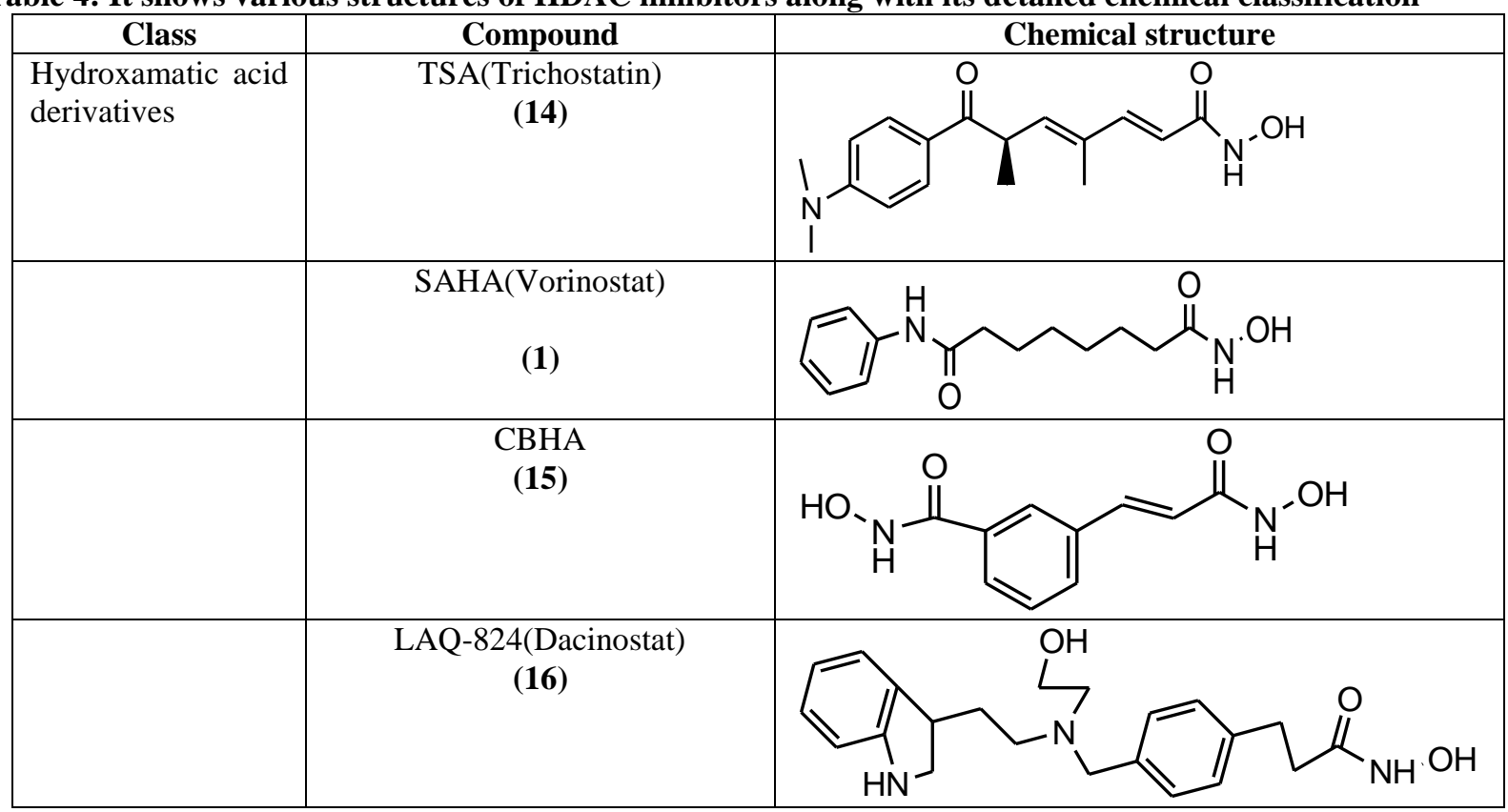




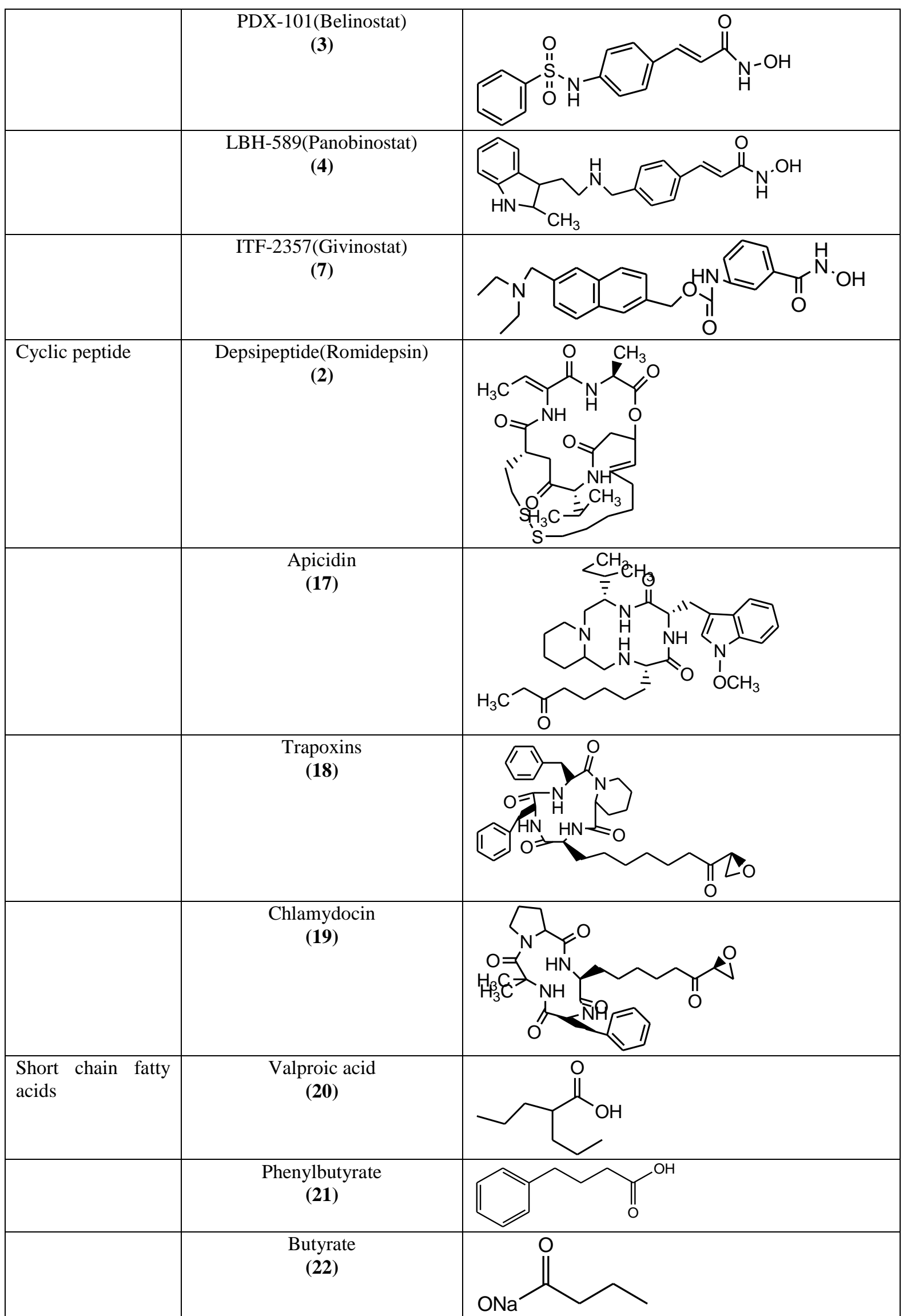




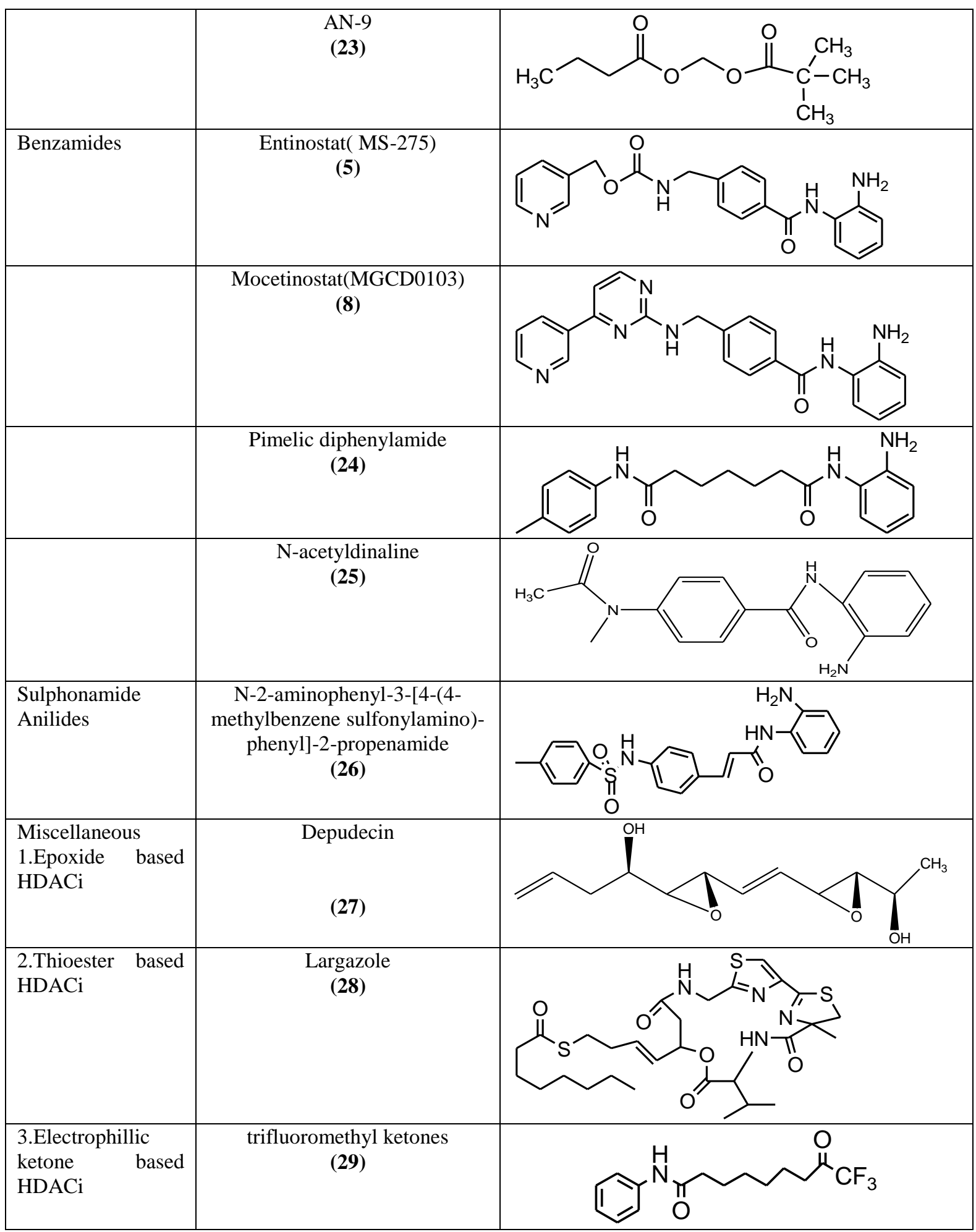

\section{Conclusion}

Epigenetic agents in combination regimens for cancer therapy are been actively studied. Histone deacetylase inhibitors are emerged as recent study of anticancer agents. They are found to interact with both the histone and non histone proteins. The development of histone deacetylase inhibitors as anti tumor drugs open a new window in cancer therapeutics. Keeping vorinostat as the basic pharmacophore a variety of analogues are prepared having improved therapeutic effect and minimal adverse effects. The impact of specific substituents of the different scaffolds on the inhibitory activity, selectivity, and side effects were also analysed. The clinical studies have shown that 
these therapeutic agents cause no or little damage to normal cells and do not show any major side effects. More efforts have been made to enhance the efficacy of HDACIs in combinational cancer treatment approaches

\section{Abbreviations}

HDACi-Histone deacetylase inhibitor, HAT histone acetyl transferase, FDA-food and drug administration, MTD-maximum tolerated dose. ZBDZinc binding domain, Ac-acetyl group, ROS-reactive oxygen species, VHL- Von Hippel Lindua, CTCLCutaneous T cell Lymphoma, DMT-DNA methyl transferases, HIF-Hypoxia inducible factor, VEGFVascular endothelial growth factor, Hsp 90- Heat shock protein 90,TSA-Trichostatin A,CDK-cyclin dependent kinase factor.

\section{Acknowledgment}

We are thankful to Dharamsinh Desai University for providing me the useful platform to carry out the work. I thank to Uka Tarsadia University for providing the necessary facilities. We sincerely appreciate the helpful advices provided by my guide for their efforts.

\section{References}

1. Bolden JE, Peart Mj, Johnstone RW, Anticancer activities of histone deacetylase inhibitors. Nat Rev Drug Discov. 2006;5:769-784.

2. Bose P, Dai Y, Grant S, Histone decaetylase inhibitor (HDACI) mechanisms of action: Emerging sights. Pharmacol Ther. 2014;1393-1403

3. Cruz FD, Matushansky I Solid tumor differentiation therapy-is it possible? Oncotarget, 2012;3:559-567.

4. Dokmanovic M, Clarke C, Marks PA Histone deacetylase inhibitors: overview and perspectives. Mol cancer Res. 2007;5:981-989.

5. Koutsounas I, Giaginis C, Patsouris E, Theocharis S, Current evidence for histone deacetylase inhibitors in pancreatic cancer. World J Gastroenterol. 2013;19:813828.

6. Marks PA, Xu WS Histone deacetylase inhibitors: Potential in cancer therapy, $J$ cell Biochem. 2009; 107:600-608

7. Xu WS, Parmigiani RB, Marks PA Histone deacetylase inhibitors: molecular mechanisms of action. Oncogene. 2007;26:5541-5552.

8. Bieliauskas AV, Pflum MK Isoform selective histone deacetylase inhibitors. Chem Soc Rev. 2008;37:14021413.

9. West AC, Johnstone RW, New and emerging HDAC inhibitors for cancer treatment. J Clin Invest. 2014;124:30-39.

10. Zhang L, Han Y, Jiang Q, Wang C, Chen X, Trend of histone deacetylase inhibitors in cancer therapy: Isoform selectivity or multitargeted strategy, Med Res Rev. 2015;35(1):63-84.

11. Kouraklis G, Theocharis S, Histone deacetylase inhibitors and anticancer therapy. Curr Med Chem Anticancer agents. 2002;2:477-484

12. Yang, X.J.; Gregoire, S. Class II histone deacetylases: From sequence to function, regulation, and clinical implication. Mol. Cell. Biol. 2005;25:2873-2884.
13. Fischle W, Kiermer, V, Dequiedt F, Verdin, E,The emerging role of class II histone deacetylases, Biochem Cell Biol. 2001;79:337-348.

14. C De Souza, HDAC inhibitors as novel cancer therapeutics, Recent Pat Anticancer Drug Discov. 2015;145-62.

15. Lian, Z.R, Xu Y.F, Wang, X.B, Gong, J.P, Liu Z.J, Suppression of histone deacetylase 11 promotes expression of il-10 in kupffer cells and induces tolerance following orthotopic liver transplantation in rats., J. Surg. Res. 2012;174:359-368.

16. Villagra, A.; Cheng, F.; Wang, H.W.; The histone deacetylase HDAC11 regulates the expression of interleukin 10 and immune tolerance, Nat. Immunol. 2009;10:92-100.

17. Buglio D, Khaskhely N.M, Voo, K.S, Martinez-Valdez H, Liu Y.J, Younes, A, HDAC11 plays an essential role in regulating ox40 ligand expression in hodgkin lymphoma, Blood. 2011;117:2910-2917.

18. Hess-Stumpp H, Bracker TU, Henderson D, Politz O:MS275 , a potent orally available inhibitor of histone deacetylases-the development of an anticancer agent. Int J Biochem Cell boil. 2007;39:1388-1405.

19. Luca DM, Davis ME, Parthun MR, Mone AP, Kitada S, Cunningham K D, The histone deacetylase inhibitor MS275 induces caspase-dependant apoptosis in B-Cell chronic lymphomatic leukemia cells, Leukemia. 2004;18:1207-1214.

20. Marks P, Rifkind RA, Richon VM, Breslow R, Miller T, Kelly WK Histone deacetylase and cancer: causes and therapies, Nat Rev Cancer. 2001;1:194-202.

21. Buggy JJ, Cao ZA, Bass KE, Verner E, Balasubramanian S, Liu L, et al;CRA-024781:a novel synthetic inhibitor of histone deacetylase enzymes with antitumoir activity invivo and invitro. Mol Cancer Ther. 2006;5:1309-1317.

22. Bolden JE, Peart MJ, Johnstone RW. Anti cancer activities of histone decaetylase inhibitors, Nat Rev Drug Discov. 2006;5:769-84.

23. Gregoretti IV, Lee YM, Goodson HV. Molecular evolution of the histone decaetylase family: functional implications of phylogenetic analysis. J Mol Biol. 2004;338:17-31.

24. Vannini A, Volpari C, Gallinari P, Substrate binding to histone deacetylases asshown by the crystal structure of the HDAC8- substrate complex, EMBO Rep. 2007;8:879-84.

25. Zain J, Kaminetzky D, O'Connor OA. Emergingroleofepige- netic therapiesincutaneous Tcellymphomas. Expert Rev Hematol. 2010;3:187-203.

26. Tan J, Cang S, Ma Y, Petrillo RL, Liu D. Novel histone deacetylase inhibitors in clinical trials as anticanceragents. J Hematol Oncol. 2010, doi:10.1186/17568722-3-5.

27. Grant S, Easley C, Kirkpatrick P, Vorinostat,.Nat Rev Drug Discov. 2007;6:21-22.

28. Sandor V, Bakke S, Robey RW, Kang MH, Blagosklonny MV, Bender J, Phase I trial of histone deacetylase inhibitor, desipeptide(FR90 NSC 630176) in patients with refractory neoplasms, Clin Cancer Res. 2008;1228:718728.

29. Marshall J L, Rizvi N, Kauh J, Dahut W, Figuera M, Kang M H. A phase I trial of depsipeptide in patients with advanced cancer. J Exp Ther Oncol. 2002;2:325-332.

30. Welsbie DS, Xu J, Chen Y, Borsu L, Scher HI, Rosen N, et al: Histone deacetylases are required for androgen receptor function in hormone sensitive and castrate resistant prostate cancer. Cancer Res. 2009;69:58-966. 
31. Buckley MT, Yoon J, Yee H, Chiriboga L, Liebes L, Ara G. The histone deacetylase inhibitor belinostat (PXD101) suppresses bladder cancer cell growth invitro and invivo. J Transl Med. 2007;5:49.

32. Dai Y, Chen S, Kramer L B, Funk VL, Dent P, Grant S Interactions between bortezomib and romidepsin and belinostat in chronic lymphocyctic leukemia cells. Clin Cancer Res. 14, 2008;14:549-558.

33. Deljigbjerg M, Gruaslund M, Christensen I J, Tjoeneland J, Buhl JP, Sehested M, Identification of predictive biomarkers for the histone deacetylase inhibitor belinostat in a panel of human cancer cell lines, Cancer Biomark. 2008;4:101-109.

34. Duan J, Friedman J, Nottingham L, Chen Z, Ara G, Van WC, Nuclear factor kappa B p65 small interfering RNA or proteasome inhibitor bortezomib sensitizes head and neck squamous cell carcinoma to classic histone deacetylase inhibitors and novel histone deacetylase inhibitor PXD101. Mol Cancer Ther. 2007;6:37-50.

35. Ramalingam SS, Belani CP, Ruel C, Frankel P, Gitilitz B, Koczywas M, et al: Phase II study of belinostat (PXD101), a histone deacetylase inhibitor,for second line therapy of advanced malignant pleural mesothelioma, $J$ Thorac Oncol. 2009;4:97-101.

36. Ma BB, Sung F, Tao Q, Poon F F, Lui - VW, Yeo W, The preclinical activity of the histone deacetylase inhibitor PXD101(belinostat)in hepatocellular carcinoma cell lines, Invest New Drugs. 2010:28(2):107-14.

37. Qian X, LaRochelle W J, Ara G, Wu F, Petersen KD, Thougaard A, et al: Activity of PXD101, a histone deacetylase inhibitor,in preclinical ovarian cancer studies. Mol Cancer Ther. 2006(5)2086-2095.

38. Qian X, Ara G, Mills E, Larochelle WJ, Linchenstien HS, Jeffers M: Activity of the histone deacetylase inhibitor belinostst (PXD101) in preclinical models of prostate cancer. Int J Cancer. 2008;122:1400-1410.

39. Ellis L, Pan Y, Smyth GK, George DJ, McCormack C, Williams - Truax R et al. Histone deacetylase inhibitor panobinostat induces clinical responses with associated alterations in gene expression profiles in cutaneous TCell lymphoma. Clin Cancer Res. 2008;14:4500-4510.

40. Rosato RR, Almenara JA, Grant S, The histone deacetylase inhibitor MS-275 promotes diffentiation or apoptosis in human leukemia cells through a process regulated by generation of reactive oxygen species and induction of p21 CIP1/WAF1,Cancer Res. 2003;63:36373645

41. Banuelos CA, Banath JP, MacPhail SH, Zhao J, Rietsema $\mathrm{T}$, Olive PL; Radiosensitization by the histone deacetylase inhibitor PCI-24781. Clin Cancer Res. 2007;13:6816-6826.

42. Adimoolam S, Siriaswad M, Chen J, Thiemann P, Ford JM, Buggy J, HDAC inhibitors PCI-24781 decreases RAD51 expression and inhibits homologous recombination, Proc Natl Acad Sci. USA. 2007;104:19482-19487.

43. Undevia SD, Janisch L, Schilsky RL, Loury D, Balasubramanian S, Mani C, Phase I study of safety, pharmacokinetics (PK) and pharmacodynamics (PD) of the histone deacetylase inhibitor (HDACi) PCI-24781.. J Clin Oncol. 2008,26(suppl),abstr\#14514.

44. Barbetti V, Gozzini A, Rovida E, Morandi A, Spinelli E, Fossati G, Selective anti-leukeamic activity of low dose histone deacerylase inhibitor ITF2357 on AML1/ETOpositive cells. Oncogene. 2008;27:1767-1778.

45. Petrini M, Galimberti S, Canestraro M, Salvi H, Palumbo GA, Nagy B. Histone deacetylase inhibitor ITF2357 is effective on the P39 cells. A gene expression study, $J$ Clin Oncol. 2008;26(15):18024-18024.

46. Salvi H, Galimberti S, Canestraro M, Nagy B, Palumbo GA, Petrini M. Bortezomib combined with histone deacetylase inhibitor ITF2357 or arsenic trioxide exerts synergistic anti proliferative and pro-apoptotic effect on P39 cells. J Clin Oncol. 2008;26(32):5156-5164.

47. Guerini V, Barbui V, Spinelli O, Salvi A, Dellacasa C, Carobbio A, et al. The histone deacetylase inhibitor ITF2357 selectively targets cells bearing mutated JAK2. Leukemia. 2008;22:740-747.

48. Golay J, Cuppini L, Leoni F, Mico C, Barbui V, Domenghini $\mathrm{M}$, et al. The histone deacetylase inhibitor ITF2357 has anti-leukemic activity in vitro and invivo and inhibits IL-6 and VEGF production by stromal cells. Leukemia. 2007;21:1892-1900.

49. Hurwitz H, Nelson B, O’Dwyner, PJ Chiorean, EG Gabrail, N Li Z, Phase I/II: The oral isotype-selective HDAC inhibitor MGCD0103 in combination with gemcitabine (Gem) in patients(pts) with refractory solid tumor. J Clin Oncol. 2008;26:abstr 4625.

50. Candelaria M, Gallardo-Rincom D, Arce C, Cetina L, Guilar-Ponce JL, Arrieta O, et al: A phase II study of epigenetic therapy with hydrazaline and magnesium valproate to overcome chemotherapy resistance in refractory solid tumors. Ann Oncol. 2007;18:1529-1538.

51. Edwards A, Li J, Atadja P, Bhalla K, Haura EB, Effect of the histone deacetylase inhibitor LBH589 against epidermal growth factor receptor dependent human lung cancer cells, Mol Cancer Ther. 2007;6:2515-2524.

52. Qlian DZ, Kato Y, Shabbeer S, WeiY, Verhuel HM, Salumbides et al: Targetting tumor angiogenesis with histone deacetylase inhibitors: the hydroxamic acid derivative LBH589.Clin Cancer Res,12,2006,634-642.

53. Geng L, Cuneo KC, Fu A, Tu T, Atadja PW, Hallahan DE; Histone deacetylase inhibitor(HDAC) LBH589 increases duration of gamma $\mathrm{H} 2 \mathrm{AX}$ foci and confines HDAC4 to the cytoplasm in irradiated non small cell lung cancer. Cancer Res. 2006;66:11298-11304.

54. Svetlana H, Tanja P, Stefan H.I, TOC $2-031$ Immunomodulatory characteristics of Resminostat, a novel HDAC inhibitor in phase II clinical development, Eu J of Cancer. 2015;51(1):11.

55. Voi, M, Fu S, Nemunaitis J, Bauman J, Bessudo A., Hamid O, Witta, S, Dy, G, Lai, C, 590 Final Results of a Phase Ib Study of CUDC-101, a Multitargeted Inhibitor of EGFR, HER2, and HDAC, in Patients with Advanced Head and Neck, Gastric, Breast, Liver, and Non-small Cell Lung Cancer. European Journal of Cancer. 2012;48(6): 181.

56. Hassig CA, Symons KT, Guo X, Nguyen PM, Annable T, Wash PL, Payne JE, Jenkins DA, Bonnefous C, Trotter C, Wang Y, Anzola JV, Milkova EL, Hoffman TZ, Dozier SJ, Wiley BM, Saven A, Malecha JW, Davis RL, Muhammad J, Shiau AK, Noble SA, Rao TS, Smith ND, Hager JH, KD5170, a novel mercaptoketone-based histone deacetylase inhibitor that exhibits broad spectrum antitumor activity in vitro and in vivo. Bioorg Med Chem Lett. 2008;18(23):6093-6.

57. Bali P, Pranpat M, Bradner J, Balasis M, Fisku W, Guo F, et al Inhibition of histone deacetylase 6 acetylates and disrupts the chaperone function of heat shock protein 90:a novel basis for antileukemia activity of histone deacetylase inhibitors, J Biol Chem. 2005;280:2672926734. 
58. Haefner M, Bluethner T, Nielderhagen M, Moebius C, Wittekind C, Mossner J, Experimental treatment of pancreatic cancer with two novel histone deacetylase inhibitors. World J Gastroenterol. 2008;14:3681-3692.

59. Kim JC, Kim DD, Lee YM, Kim TW, Cho DH, Kim MB, Evaluation of novel histone deacetylase inhibitors as therapeutic agents for colorectal adrenocarcinomas compared to established regimens with the histoculture drug response array,Int J Colorectal Dis. 2009;24:209218.

60. Meeran S M, Patel S N, Li Y, Shukla S, Tollefsbol TO Bioactive dietary supplements reactivate ER expression in ER-negative breast cancer cells by active chromatin modifications PLoS one. 2012;7:e37748.
61. Bangert A, Christofanon S, Eckhardt I, Akbari BA, Kolodzeij S, Histone deacetylase inhibitors sensitize glioblastoma cells to TRAIL -induced apoptosis by cmyc-mediated downregulation of cFLIP. Oncogene. 2012;31:4677-4688.

62. Goldberg AD, Allis CD, Bernstein E, Epigenetics:a landscape takes shape. Cell. 2007;128:635-638. 